\title{
Grain yield, agronomic traits, and protein content of two- and six-row barley genotypes under terminal drought conditions
}

\author{
Vesna Kandic ${ }^{1 *}$, Dejan Dodig ${ }^{1}$, Mile Secanski ${ }^{1}$, Slaven Prodanovic ${ }^{2}$, Gordana Brankovic ${ }^{2}$, \\ and Primoz Titan ${ }^{3}$ \\ 'Maize Research Institute "Zemun Polje”, Slobodana Bajića 1, 11080 Belgrade, Serbia. \\ "Corresponding author (vesna.kandic@gmail.com). \\ ${ }^{2}$ University of Belgrade, Faculty of Agriculture, Nemanjina 6, 11080 Belgrade, Serbia. \\ ${ }^{3}$ RGA Research, Genetics and Agrochemistry Ltd., Brodarska ulica 27, Krog, 9000 Murska Sobota, Slovenia.
}

Received: 17 June 2019; Accepted: 26 August 2019; doi:10.4067/S0718-58392019000400648

\begin{abstract}
Small grain cereals in lower latitude areas usually mature under terminal drought conditions that affect their agronomic performance. An experiment was conducted to compare agronomic traits, grain yield, and protein content under control and terminal drought conditions of 15 two-row and 10 six-row barley (Hordeum vulgare L.) genotypes. The experiment was set up at two locations for two growing seasons $(2011,2012)$ and two treatments. One treatment was terminal drought (D) simulated by the mechanical removal of all leaf blades $7 \mathrm{~d}$ after the heading of each genotype, and a control (C) treatment in which plants were left intact. On average, defoliation caused a greater reduction in grain yield and protein content of the six-row genotypes (37.6\% and $12.3 \%$, respectively) than the two-row genotypes ( $28.8 \%$ and $7.1 \%$, respectively). On the other hand, test weight of six-row genotypes showed better tolerance to terminal drought. According to the multivariate function analysis, the genotypes of both types of barley with a high test weight, a longer uppermost internode, and a longer grain filling period had high protein content under terminal drought stress. In contrast to six-row genotypes, it is possible to breed two-row genotypes that not only have high grain yield but also high protein content under both optimal and drought stress conditions.
\end{abstract}

Key words: Abiotic stress, barley quality, grain filling, grain yield, Horedeum vulgare.

\section{INTRODUCTION}

Barley (Hordeum vulgare L.) has three main uses: feed, food, and malt production (Newton et al., 2011). Barley grain has lower protein and energy levels than wheat, but it is the only cereal and the only staple food resource in arid and semi-arid regions of some developing countries. Climate change will be a significant challenge for delivering grain with consistent yield and quality in the future due to the complex effects of atmospheric $\mathrm{CO}_{2}$ and changing temperature and rainfall patterns on barley development (Nuttall et al., 2017). This is the case in Mediterranean and Southeastern European environments where small grain cereals usually mature under terminal drought conditions. Studies showed that yield components and protein content (PC) decreased and increased, respectively, when barley was subjected to water stress after anthesis (Samarah et al., 2009; Wu et al., 2017). Dry matter for grain filling is a result of a post-anthesis photosynthetic activity and remobilization of storage reserves deposited prior to anthesis. If climatic conditions (predominantly water scarcity and enhanced temperatures) are limiting, the contribution of current photosynthesis to grain filling declines and the remobilization of stored carbohydrates from senescent tissues increases (Merah et al., 2017). During the vegetative and early reproductive stages of cereal development, assimilated $\mathrm{C}$ is temporarily stored as carbohydrate in vegetative 
sink tissues, such as the stem and leaf sheaths, and those reserves are subsequently remobilized for the transport to reproductive sink tissues and filling the grain during the later stages of plant development (Scofield et al., 2009). Arisnabarreta and Miralles (2008) and Nuttall et al. (2017) reported that barley yield (carbohydrate deposition) in a wide range of environments was considered to be limited by the number and capacity of grains to store DM (sink-limitation) rather than the availability to assimilate for grain filling (source-limitation). In contrast, protein deposition is largely a limited source and relies on $\mathrm{N}$ reserves accumulated in the leaves and stems in the pre-anthesis phase (Kohl, 2015). At the end of the grain filling process, mature barley grain consists of starch, proteins, $\beta$-glucan, and minor components. Starch is a major storage component in the starchy endosperm and increased starch content usually results in larger grains. Test weight (TW) is grain density or weight per unit of volume of a grain at a standardized moisture level. Grains with a higher TW have a higher percentage of large, plump kernels with a greater proportion of starch-rich endosperm and lower PC. This is the reason why TW, in addition to PC, is an important indicator of barley quality.

Based on spike morphology, that is, floret fertility, barley is divided in two types. In two-row barley genotypes, only the central spikelet is fertile, while the remaining two lateral spikelets are either sterile or reduced. On the other hand, in six-row barley genotypes, in addition to the central spikelet, two lateral spikelets are also fertile and can develop grain. These two types generally differ in their end use: six-row barley is mainly used as feed due to its higher grain PC and less uniform grain size and weight compared with two-row barley (Lang et al., 2013; Zwirek et al., 2019), while two-row barley is more often used as a malting material in beer production, producing high malt extract, lighter color, and less enzyme content than the six-row type (Gupta et al., 2010). The aim of this study was to evaluate the effect of terminal drought conditions simulated by defoliation on grain yield, agronomic traits, and protein content of 25 barley genotypes of both barley types and to examine a correlation of these traits under optimal and stress conditions.

\section{MATERIALS AND METHODS}

\section{Plant material and growing conditions}

The experiment consisted of 15 two-row and 10 six-row winter barley genotypes (Kandic et al., 2018) and was conducted

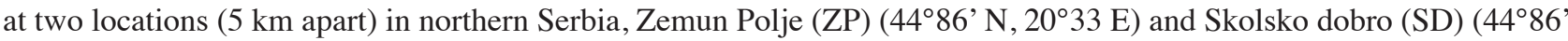
$\mathrm{N}, 0^{\circ} 28 \mathrm{E}$ ) during the 2010-2011 and 2011-2012 growing seasons. The experiment used a randomized block design with two replicates and two treatments. Each plot consisted of five $1 \mathrm{~m}$ long rows, $20 \mathrm{~cm}$ spacing, and a typical seeding rate of 350 seeds $\mathrm{m}^{-2}$. The first treatment was the control (C) with intact plants, while all leaf blades were manually removed $7 \mathrm{~d}$ after the heading of each genotype in the second treatment (D). Drought conditions during grain filling were simulated by inhibiting current photosynthesis (as a result of defoliation) and plants were forced to rely on mobilizing stem reserves to maintain grain filling (Dodig et al., 2016; 2018).

Soil at the $\mathrm{ZP}$ site is a slightly calcareous Chernozem (CaCO3 1.5\%) with 3.0\% humus content, $\mathrm{pH}(\mathrm{KCl}) 7.1$, soil

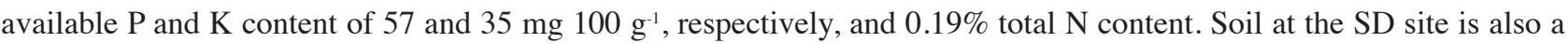
Chernozem with higher $\mathrm{Ca}\left(\mathrm{CaCO}_{3} 6.4 \%\right)$, lower humus (2.5\%), soil pH $(\mathrm{KCl}) 7.4$, soil available $\mathrm{P}$ and $\mathrm{K}$ content of 26 and $22 \mathrm{mg} 100 \mathrm{~g} \mathrm{~g}^{-1}$, respectively, and $0.15 \%$ total $\mathrm{N}$ content. Soil characteristics at the sites correspond to the $60 \mathrm{~cm}$ layer. Fertilizer rates were determined based on the soil chemical characteristics and available amounts of $\mathrm{N}, \mathrm{P}$, and $\mathrm{K}$ in the

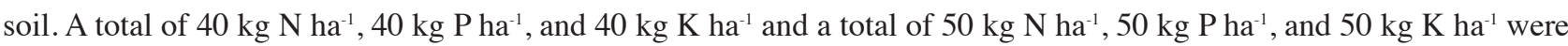
applied prior to sowing in the ZP and SK sites, respectively. The top dressing was applied at $30 \mathrm{~kg} \mathrm{~N}^{-1}$ at both sites in March or April. Standard cropping practices were applied to keep plots pest and disease free.

Genotypes were sown in late October and harvested in late June of the following year. To prevent the reduction of the accumulated reserve and storage capacity in stems, plots were manually irrigated from early March (beginning of tillering) to the end of April (beginning of heading) when water in the top $0.75 \mathrm{~m}$ soil layer had decreased below $50 \%$ field capacity. Soil moisture content was determined weekly by the gravimetric method from samples collected at three depths $(0.25,0.50$, and $0.75 \mathrm{~m})$ and at a frequency depending on the rainfall pattern. Two irrigation events of $50 \mathrm{~mm}$ added water and another irrigation event of $30 \mathrm{~mm}$ added water were applied in the 2010-2011 and 2011-2012 seasons, respectively.

The meteorological data for the winter barley crop cycle in spring (March-June) were recorded at the nearest weather station of the Republic Hydrometeorological Service of Serbia, approximately $5 \mathrm{~km}$ away from both experimental sites. Averaged daily mean temperatures during grain filling (May and June) were $19.9{ }^{\circ} \mathrm{C}(2011)$ and $20.8{ }^{\circ} \mathrm{C}(2012)$, while 
the number of days with the maximum temperature above $30{ }^{\circ} \mathrm{C}$ in the May-June period were 7 and $15 \mathrm{~d}$, respectively (Kandic et al., 2018). Higher temperatures in 2012 were combined with a lower amount of precipitation during grain filling (98 mm in $2012 \mathrm{vs.} 118 \mathrm{~mm}$ in 2011). To obtain more precise temperature information during grain filling, average temperatures $(\mathrm{Ta})$ for every genotype were calculated using daily mean temperatures during the whole grain filling period of a specific genotype.

\section{Data collection}

Spike sampling was initiated at the start of defoliation and continued at a 5-d interval until full maturity (a total of nine samples were drawn for each plot). Five uniform plants per plot were collected from the center of the plot at each sampling and used to obtain the number of sterile kernels (SK, excluding lateral florets), number of fertile kernels (KN), and length of the uppermost internode (LI, length between the last developed node and the collar, $\mathrm{cm}$ ). Grain yield (YLD, $\mathrm{kg} \mathrm{ha}^{-1}$ ), test weight (TW, $\left.\mathrm{kg} \mathrm{hL}^{-1}\right)$, and total protein content (PC, \%) were calculated at full maturity for each plot based on the $13 \%$ moisture level. Protein content was determined by near infrared spectroscopy (Chopin Technologies). The grain filling duration (GFD) was calculated as accumulated growing degree days (GDD) from heading. The GDD was computed with $0{ }^{\circ} \mathrm{C}$ as a base temperature (Grigorieva et al., 2010; Ibrahim et al., 2018) on the basis of a daily mean temperature by the following formula: $T n=((\operatorname{Tmax}+\operatorname{Tmin}) / 2)-T b$ where $T n$ is the daily degree-day, $\operatorname{Tmax}$ is the maximum daily temperature, $T \min$ is the minimum daily temperature, and $T b$ is the base temperature.

\section{Data analysis}

To evaluate significant differences among genotypes, treatments, and environments (year-location combination), a threeway ANOVA was performed. The significance of differences between treatments $\mathrm{C}$ and $\mathrm{D}$ and between two- and six-row barley genotypes was estimated by the t-test with letter groupings generated by $5 \%$ and $1 \%$ levels of significance. The principal component analysis (PCA) described by Yan and Rajcan (2002) was used to visually display relationships between observed traits. Separate biplots were constructed for two treatments and barley types. A positive correlation between two traits was represented by an acute angle between them, while an obtuse angle represented a negative correlation. All calculations were made with the Minitab (trial version 17) and Excel software packages.

\section{RESULTS AND DISCUSSION}

The greatest average reduction of studied traits due to defoliation across years and sites for both barley types was recorded for YLD (37.6\% and 28.8\% in the groups of six-row and two-row genotypes, respectively) (Figure 1). On the other hand, KN was almost at the same level in both treatments (Figure 1). Yield reductions were similar to results indicated by Gonzalez et al. (2007), who reported that the average grain yield reduction for six- and two-row barley after applying terminal drought stress was $38.9 \%$ and $27.2 \%$, respectively. Stress caused by defoliation increased SK of six-row genotypes by $16.7 \%$ and prolonged GFD by $1.09 \%$. In two-row barley, SK increased by $7.4 \%$, while GFD after defoliation was slightly shorter (0.45\%). Samarah et al. (2009) reported that GFD for barley genotypes (two- and six-row) grown under water stress treatments was shorter in both types than in the well-watered treatment. In the stress treatment, shortening

Figure 1. Percentage average decrease/increase of investigated traits of two-row (black bars) and six-row (white bars) barley genotypes in defoliation $v s$. control treatment.

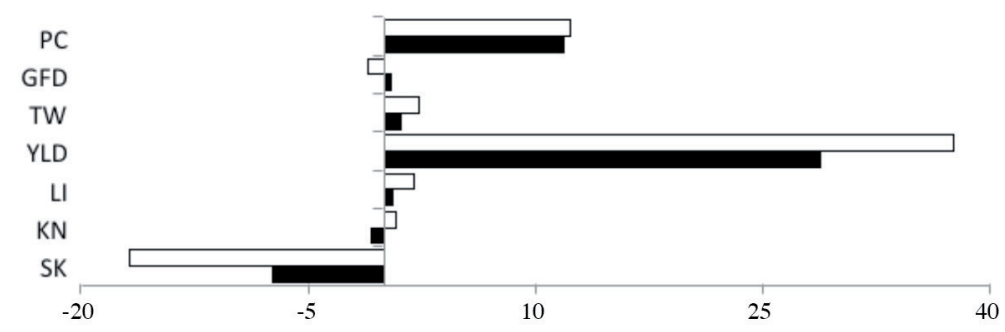

PC: Protein content; GFD: grain filling duration; TW: test weight; YLD: grain yield; LI: length of uppermost internode; KN: number of fertile kernels; SK: number of sterile kernels. 
of the uppermost internode was greater in six-row barley (2.0\%) than in two-row barley $(0.6 \%)$, as well as TW reduction (2.3\% and $1.1 \%$, respectively). Moreover, TW decreased more in six-row barley (2.3\%) than in two-row barley (1.1\%).

The PC decrease was slightly higher in the group of six-row genotypes (12.3\%) than in two-row genotypes (11.9\%). Other authors generally reported that PC was higher under (terminal) drought conditions (Afshari-Behbahanizadeh et al.,

Figure 2. Mean values of investigated traits across years $(2011,2012)$ and treatments (control C, defoliation D), and averaged (C aver and $\mathrm{D}$ aver) for both years.
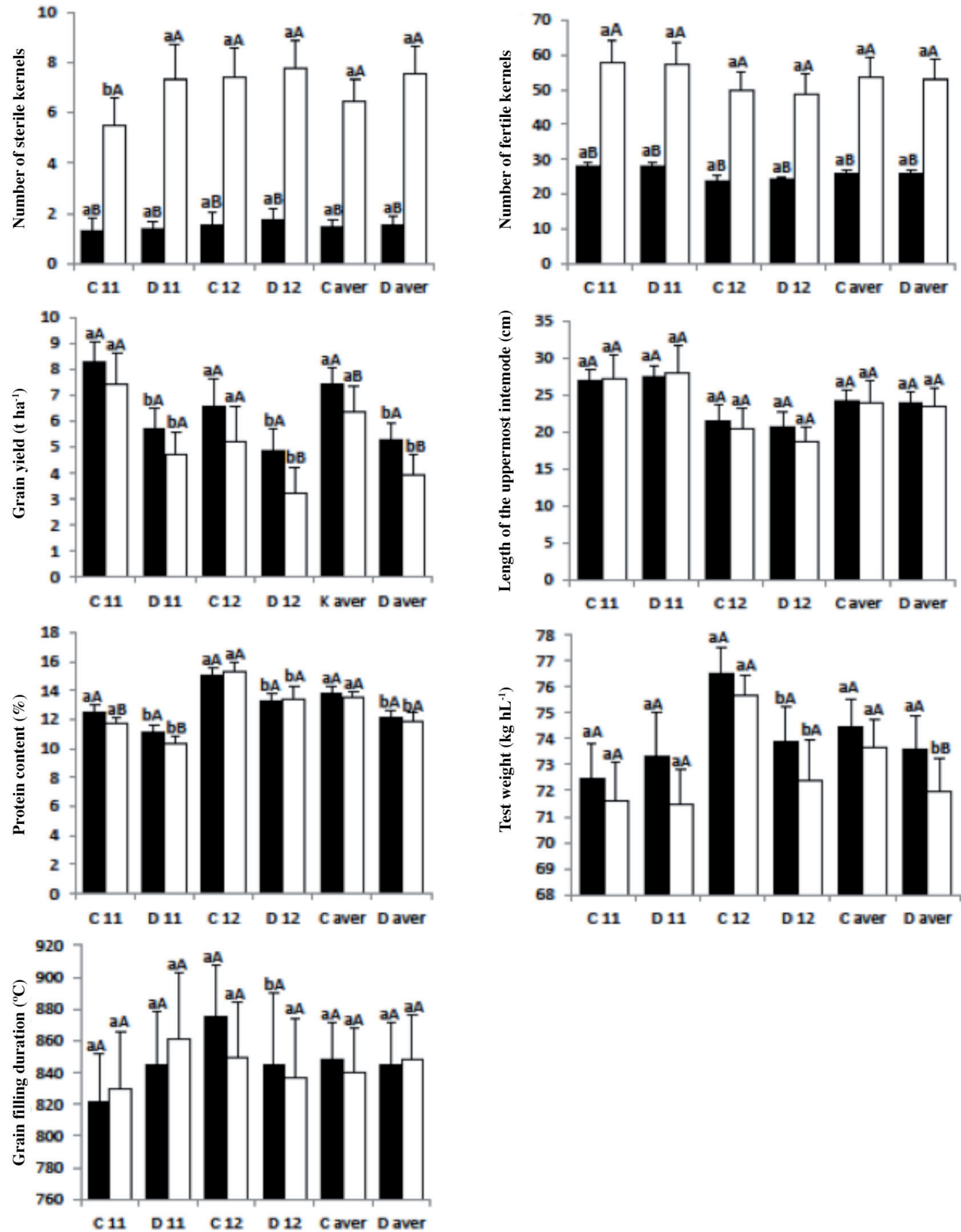

Uppercase letters indicate a difference between two-row (black bars) and six-row (white bars) barley genotypes separately for each treatment. Lowercase letters indicate a difference between the two treatments separately for each barley type. The same lowercase or uppercase letters are not significantly different at $\mathrm{P}<0.05$ according to the t-test. 
2016). However, since protein deposition mostly relies on $\mathrm{N}$ reserves accumulated in leaves and stems (Distelfeld et al., 2014), removing all the green leaves to simulate drought conditions, as in our case, probably caused decreased PC in defoliation compared with the control treatment.

A comparative analysis of two barley types under different conditions was performed. Figure 2 shows mean values of investigated traits over 2 yr $(2011,2012)$ and treatments (control, defoliation) and averaged for both years. Significant (P $<0.05)$ differences between the two barley types were obtained for most traits. The average number of SK in both years and both treatments was significantly higher in the group of six-row genotypes than in the group of two-row genotypes. Several authors (Arisnabarreta and Miralles, 2006) reported that spikelet abortion was generally higher in six-row barley types because they have more fertile spikelet primordia per spike (Koppolu et al., 2013; Alqudah and Schnurbusch, 2014). In 2011, a significant difference was recorded in the group of six-row genotypes between treatments $C$ (5.5) and $\mathrm{D}$ (7.4) for SK, while the difference between treatments C and D s was nonsignificant (1.3 vs. 1.4) in the group of tworow genotypes. Both barley types had higher SK in 2012 than in 2011 when twice as many days with temperatures above $30{ }^{\circ} \mathrm{C}$ were recorded. Two-row barley had higher SK by $18.8 \%$ and $17.6 \%$ in 2012 than in 2011 in treatments C and D, respectively. On the other hand, SK of six-row barley was higher by $25.6 \%$ and 3.9\% in 2012 than in 2011 in treatments C and D, respectively. In 2012, the difference between the same barley types under different treatments was nonsignificant.

The two barley types were significantly $(\mathrm{P}<0.01)$ different regarding the number of fertile kernels $(\mathrm{KN})$ per spike in both treatments. On average, higher $\mathrm{KN}$ values were recorded across years in six-row genotypes (53.6 and 53.1 in $\mathrm{C}$ and D, respectively) than in two-row genotypes (26.0 and 26.2 in C and D, respectively). Barley row type, that is, $\mathrm{KN}$ is controlled by at least five loci: Six-rowed spike 1 (Vrs1 [syn =HvHox1]), Vrs2, Vrs3, Vrs4, and Intermedium spike-c $($ Int-c $[s y n=V r s 5])$, and all five genes have been identified (Sakuma et al., 2017). The barley spike is formed during the vegetative stage and depends on the environmental conditions under which the morphogenesis of the generative organs takes place during the orthogenetic process. Arisnabarreta and Miralles (2008) considered that the critical period for the grain number of six-row types was $30 \mathrm{~d}$ before flowering and even earlier for two-row types (between 40 and $10 \mathrm{~d}$ before flowering). The number of fertile spikelets was affected by the number of assimilates available to the spike in the early stages of its development (Arisnabarreta and Miralles, 2008). In the present study, defoliation on the seventh day after heading did not reduce $\mathrm{KN}$ because the final number of grains had already been formed. According to Alqudah and Schnurbusch (2014), actual anthesis/fertilization events in winter barley occur before flowering (when anther extrudes), for example, after the awn tipping stage or heading (according to the Zadoks scale GS49; Zadoks et al., 1974).

The TW is grain density or weight per unit of volume of a grain at a standardized moisture level. On average, across years and treatments, higher values for TW were recorded for two-row genotypes $\left(74.0 \mathrm{~kg} \mathrm{hL}^{-1}\right)$ than for six-row genotypes $\left(72.8 \mathrm{~kg} \mathrm{hL}^{-1}\right)$. In 2011, there was a nonsignificant difference between the two types, as well as within the same type in treatments C and D. In 2012, there was a significant difference $(\mathrm{P}<0.05)$ within the same barley type (either two- and/ or six-row) in treatments $\mathrm{C}$ and $\mathrm{D}$, but there was a nonsignificant difference between the two types in the same treatment (either $\mathrm{C}$ and/or D). Overall for both years, two-row genotypes had similar TW values in treatments C and D (74.5 and $73.6 \mathrm{~kg} \mathrm{hL}^{-1}$, respectively), while six-row genotypes had significantly $(\mathrm{P}<0.05)$ lower values in the $\mathrm{D}$ treatment than in the $\mathrm{C}$ treatment (71.9 and $73.6 \mathrm{~kg} \mathrm{hL}^{-1}$, respectively); this suggests that two-row types were less sensitive/susceptible to drought stress during grain filling. The higher TW values for two-row types in both treatments and both years are in accordance with the results obtained by other authors, who reported that two-row types generally produced larger seeds with a higher TW (Frégeau-Reid et al., 2001; Djekic et al., 2017).

Given that protein deposition relies on $\mathrm{N}$ reserves accumulated in leaves and stems in the pre-anthesis phase, we compared barley types for LI) in both treatments. Previous studies performed on wheat genotypes (Dodig et al., 2016; 2017) showed that one of the most important traits for grain weight per spike was peduncle length in both terminal drought and control treatments. Other authors (Nikkhah et al., 2010; Shobbar et al., 2017) reported that peduncle length had one of the highest direct effects on grain yield in both six-row and two-row barley genotypes under terminal drought conditions. Averaged across years, defoliation did not significantly influence LI of the barley types. The LI values established in two-row genotypes were 24.2 and $24.1 \mathrm{~cm}$ in treatments $\mathrm{C}$ and $\mathrm{D}$, respectively, while the corresponding values in sixrow genotypes were 23.9 and $23.4 \mathrm{~cm}$. The difference between two types in the same treatment was also nonsignificant. Averaged across treatments and barley types, the LI of the studied genotypes was shorter by $25.5 \%$ in 2012 when higher temperatures were combined with lower precipitation during grain filling compared with 2011. Modarresi et al. (2010) 
reported that wheat peduncle length was highly sensitive to heat stress during grain filling and decreased by $20.2 \%$. The only significant influence of defoliation $(\mathrm{P}<0.05)$ was recorded in $\mathrm{D} 12$ when six-row genotypes had shorter LI than tworow genotypes (18.8vs. $20.7 \mathrm{~cm})$.

The combined PCs for 2 yr were significantly different $(\mathrm{P}<0.01)$ for the same barley type between treatments $\mathrm{C}$ and D. On average, two-row barley PC was not significantly higher (12.9\%) than 6-row barley (12\%). The average PC values obtained by other authors for both barley types/genotypes varied from 12\% to 14\% (Ingvordsen et al., 2016). FrégeauReid et al. (2001) reported that PC for two-row barley was greater than for six-row barley, while in the study by Lahouar et al. (2017), the value was higher in six-row genotypes than in two-row barley genotypes. Elia et al. (2010) carried out a study of cross-breeding European two-row barley with American six-row barley and found that the high protein allele was carried by the two-row parent. Averaged for both years and types, PCs were lower in treatment D than in treatment C $(12 \%$ and $13.6 \%$, respectively). In 2011, there was a significant $(\mathrm{P}<0.01)$ difference between the two barley types within the same treatment in favor of the two-row barley type, while in 2012, this difference was nonsignificant, and six-row genotypes had a slightly higher PC.

Averaged across years, there were nonsignificant differences between barley types for GFD in both treatments in 2011. In 2012, two-row genotypes had a significantly $(\mathrm{P}<0.05)$ longer grain filling period in treatment $\mathrm{C}$ than in treatment $\mathrm{D}$, but the group of six-row genotypes maintained grain filling at an approximately similar level in both treatments (D and C). Dias and Lidon (2009) reported that drought after anthesis shortened the grain filling period; however, according to our results, this happened only in 2012 when drought stress was accompanied with higher mean temperatures.

The highest mean YLD (8239 $\left.\mathrm{kg} \mathrm{ha}^{-1}\right)$ was recorded in two-row genotypes in C11, and the lowest (3204 $\left.\mathrm{kg} \mathrm{ha}^{-1}\right)$ in six-row genotypes in D12. Averaged for the $2 \mathrm{yr}$, there were significant differences between two- and six-row types in treatments $\mathrm{C}(\mathrm{P}<0.05)$ and $\mathrm{D}(\mathrm{P}<0.01)$. In treatment $\mathrm{D}$, two-row genotypes had $25.1 \%$ higher yield than six-row genotypes (5279 and $3954 \mathrm{~kg} \mathrm{ha}^{-1}$, respectively). On the other hand, yields recorded in treatment $\mathrm{C}$ were 7419 and 6336 $\mathrm{kg} \mathrm{ha}^{-1}$, respectively, which means that the yield established in two-row genotypes was higher by $14.6 \%$. The higher yield of two-row genotypes is in accordance with results reported by Bratkovic (2014), but contrary to results reported by Samarah et al. (2009). In 2011, two- and six-row genotypes had a significantly $(\mathrm{P}<0.01)$ lower yield in treatment $\mathrm{D}$ than in treatment $\mathrm{C}$, while there was nonsignificant difference for yield when the two types were compared within a treatment. In 2012 , both barley types had a significantly $(\mathrm{P}<0.05)$ lower yield in treatment $\mathrm{D}$ than in treatment $\mathrm{C}$. In 2012 , six-row genotypes had a significantly lower yield than two-row genotypes in both treatments (C: $5241 \mathrm{~kg} \mathrm{ha}^{-1} v s .6599 \mathrm{~kg} \mathrm{ha}^{-1}$, respectively, and D: $3204 \mathrm{~kg} \mathrm{ha}^{-1} v s .4853 \mathrm{~kg} \mathrm{ha}^{-1}$, respectively).

The results of three separate factorial ANOVA for the two barley types (Table 1) indicate that the environment factor (on average $36.9 \%$ and $36.0 \%$ for two- and six-row genotypes, respectively) had the most significant influence on the variability of all the traits, followed by the genotype factor (on average $13.3 \%$ and $19.8 \%$ for two- and six-row genotypes, respectively) and the $\mathrm{G} \times \mathrm{E}$ interaction (11.5\% and $9.4 \%$, respectively). The great effect of environment on most traits was probably due to the contrasting seasons in which the experiments were set up. The influence of the $\mathrm{G} \times \mathrm{T}$ interaction on most of the traits was nonsignificant and this indicates that there was nonsignificant difference among the investigated genotypes in their response to stress caused by defoliation. These results are different from those obtained when two- and six-row genotypes were observed together and in which the most significant influence on variability was the genotype factor and the treatment factor had a greater influence than the interactions (Kandic et al., 2018). Most of the YLD variation in the two-row group was associated with the treatment (31.5\%) and in the six-row group with the environment (35.3\%). The environment had the strongest influence on PC as well as on TW and LI for both barley types. Furthermore, the environment factor had the highest impact on $\mathrm{KN}$ of two-row genotypes (71.7\%), while the variability of KN in sixrow genotypes was mostly influenced by the genotype (54.3\%). The variability of SK in both types was mostly influenced by genotypic differences. The effect of the genotype was significant for all measured traits except for GFD, indicating a high degree of genetic variation that could be exploited in the breeding program of two- and six-row barley.

\section{Multivariate analysis}

A PCA was performed to determine the interrelationship between YLD, agronomic traits, and PC under control and stress conditions for each barley type (Figure 3). In the two-row barley group in treatment $\mathrm{C}$, the strongest correlations were between GFD and LI (positive) and between PC and TW (negative). The YLD had a positive correlation with KN, 
Table 1. ANOVA for yield, agronomic traits, and protein content of 15 two-row and 10 six-row barley genotypes from control and defoliated plants grown in four environments (year-location combinations).

\begin{tabular}{|c|c|c|c|c|c|c|c|c|c|c|c|c|c|c|c|}
\hline \multirow[b]{2}{*}{ Trait } & & \multicolumn{2}{|c|}{ G } & \multicolumn{2}{|c|}{$\mathrm{T}$} & \multicolumn{2}{|c|}{$\mathrm{E}$} & \multicolumn{2}{|c|}{$\mathrm{G} \times \mathrm{T}$} & \multicolumn{2}{|c|}{$\mathrm{G} \times \mathrm{E}$} & \multicolumn{2}{|c|}{$\mathrm{T} \times \mathrm{E}$} & \multicolumn{2}{|c|}{$\mathrm{G} \times \mathrm{T} \times \mathrm{E}$} \\
\hline & & 2 & 6 & 2 & 6 & 2 & 6 & 2 & 6 & 2 & 6 & 2 & 6 & 2 & 6 \\
\hline \multirow[t]{2}{*}{ SK } & F-test & $* *$ & $* *$ & $\mathrm{~ns}$ & $* *$ & $* *$ & $* *$ & ns & ns & ns & $* *$ & $*$ & $* *$ & ns & $*$ \\
\hline & $\sigma^{2}(\%)$ & 24.0 & 20.8 & 0.8 & 7.8 & 7.8 & 18.6 & 3.1 & 3.2 & 19.0 & 15.0 & 3.8 & 5.3 & 9.6 & 12.2 \\
\hline \multirow[t]{2}{*}{$\mathrm{KN}$} & F-test & $* *$ & $* *$ & ns & ns & $* *$ & $* *$ & ns & ns & ns & $* *$ & ns & ns & ns & $\mathrm{ns}$ \\
\hline & $\sigma^{2}(\%)$ & 18.8 & 54.3 & 0.2 & 0.1 & 71.7 & 34.0 & 0.7 & 0.3 & 3.4 & 4.8 & 0.1 & 0.6 & 1.6 & 1.5 \\
\hline \multirow[t]{2}{*}{ LI } & F-test & $* *$ & $* *$ & ns & $* *$ & $* *$ & $* *$ & $\mathrm{~ns}$ & $*$ & $* *$ & $* *$ & $* *$ & $* *$ & ns & $* *$ \\
\hline & $\sigma^{2}(\%)$ & 12.6 & 26.2 & 0.0 & 0.2 & 72.2 & 65.6 & 0.4 & 0.4 & 8.4 & 3.2 & 1.2 & 2.0 & 1.0 & 1.0 \\
\hline \multirow[t]{2}{*}{ YLD } & F-test & $* *$ & $* *$ & $* *$ & $* *$ & $* *$ & $* *$ & $* *$ & $* *$ & $* *$ & $* *$ & $* *$ & $* *$ & $* *$ & $* *$ \\
\hline & $\sigma^{2}(\%)$ & 7.2 & 13.0 & 31.5 & 27.8 & 24.6 & 35.3 & 3.6 & 1.8 & 15.8 & 14.5 & 1.1 & 0.7 & 9.6 & 3.5 \\
\hline \multirow[t]{2}{*}{ TW } & F-test & $* *$ & $* *$ & $* *$ & $* *$ & $* *$ & $* *$ & ns & $\mathrm{ns}$ & $\mathrm{ns}$ & $\mathrm{ns}$ & $* *$ & $* *$ & $\mathrm{~ns}$ & $\mathrm{~ns}$ \\
\hline & $\sigma^{2}(\%)$ & 18.5 & 17.2 & 2.7 & 10.8 & 23.0 & 25.8 & 1.1 & 1.8 & 9.7 & 3.7 & 19.9 & 21.3 & 5.8 & 7.6 \\
\hline \multirow[t]{2}{*}{ GFD } & F-test & $\mathrm{ns}$ & $\mathrm{ns}$ & $\mathrm{ns}$ & ns & $* *$ & $*$ & ns & $* *$ & ns & $* *$ & $* *$ & $* *$ & ns & $* *$ \\
\hline & $\sigma^{2}(\%)$ & 7.5 & 3.9 & 0.1 & 0.4 & 7.8 & 4.8 & 5.9 & 9.3 & 19.4 & 20.9 & 6.1 & 5.8 & 19.0 & 31.0 \\
\hline \multirow[t]{2}{*}{$\mathrm{PC}$} & F-test & $* *$ & $* *$ & $* *$ & $* *$ & $* *$ & $* *$ & ns & ns & ns & $\mathrm{ns}$ & $* *$ & $* *$ & $\mathrm{~ns}$ & $\mathrm{~ns}$ \\
\hline & $\sigma^{2}(\%)$ & 4.4 & 2.9 & 21.2 & 13.9 & 51.3 & 68.2 & 1.8 & 1.3 & 4.7 & 3.7 & 1.8 & 1.7 & 1.3 & 2.0 \\
\hline Average & $\sigma^{2}(\%)$ & 13.3 & 19.8 & 8.1 & 8.7 & 36.9 & 36.0 & 2.4 & 2.6 & 11.5 & 9.4 & 4.8 & 5.3 & 6.8 & 8.4 \\
\hline
\end{tabular}

*, **Significance at the 0.05 and 0.01 probability levels, respectively; ns: nonsignificant.

G: Genotype; T: treatment; E: environment; $\sigma^{2}(\%)$ : percentage of explained variance; SK: number of sterile kernels; KN: number of fertile kernels; LI: length of uppermost internode; YLD: grain yield; TW: test weight; GFD: grain filling duration; PC: protein content.

SK, and PC. In treatment D, the strongest positive correlations were between LI and SK, and the strongest negative between TW, PC, and KN. The YLD was positively associated with TW, PC, and GFD. These results suggest that tworow genotypes could have both high yields and PCs under both optimal and drought stress conditions. Under defoliation, LI had a greater impact on PC compared with optimal conditions, probably due the fact that after the removal of the leaf blades, protein deposition, as a limited source, only relied on $\mathrm{N}$ reserves accumulated in the stems. Besides genotypes with longer LI, those which could prolong the grain filling period under terminal drought stress also had a higher PC and YLD. When testing the population of malting barley in environments suffering severe drought, Moody et al. (2001) reported that grain size, as a primary contributor to final YLD, had been enhanced by longer peduncles, less kernels per spike, and earlier maturity.

For the six-row genotypes in the control treatment, the strongest positive correlation was detected between KN and LI, while the strongest negative correlations were established between PC, TW, and YLD. Although no difference was found between the two barley types for GFD, a strong association between YLD and GFD indicates that high yielding genotypes (in both barley types) under optimal conditions would tend to have a longer grain filling period. Under defoliation, the strongest positive correlation was between KN and SK, as well as between GFD and TW. The YLD had the strongest negative association with KN and SK. Moreover, YLD and PC were also negatively correlated, but not so strongly as in treatment C. On the other hand, PC was positively associated with all traits, except YLD. In contrast to two-row barley, this means that it would be very difficult to develop six-row barley genotypes with both high yield and PC.

Across two- and six-row genotypes, a positive correlation between PC and Ta under defoliation is in accordance with the results indicated by Reinhardt et al. (2013), who reported that high temperatures during the grain filling period prior to harvest increased the PC of barley genotypes. Our results suggest that genotypes of both barley types with high TW, longer LI, and ability to prolong the grain filling period under stress conditions, would have a higher PC. High mean temperatures under terminal drought stress influenced YLD of both barley types to a greater extent than under optimal growing conditions. 
Figure 3. Interrelationship between grain yield, agronomic traits, and protein content (averaged across years and locations) for two-row barley genotypes grown under control conditions (a); two-row barley genotypes grown under terminal drought conditions (b); six-row barley genotypes grown under control conditions (c); and six-row barley genotypes grown under terminal drought conditions $(\mathbf{d})$.
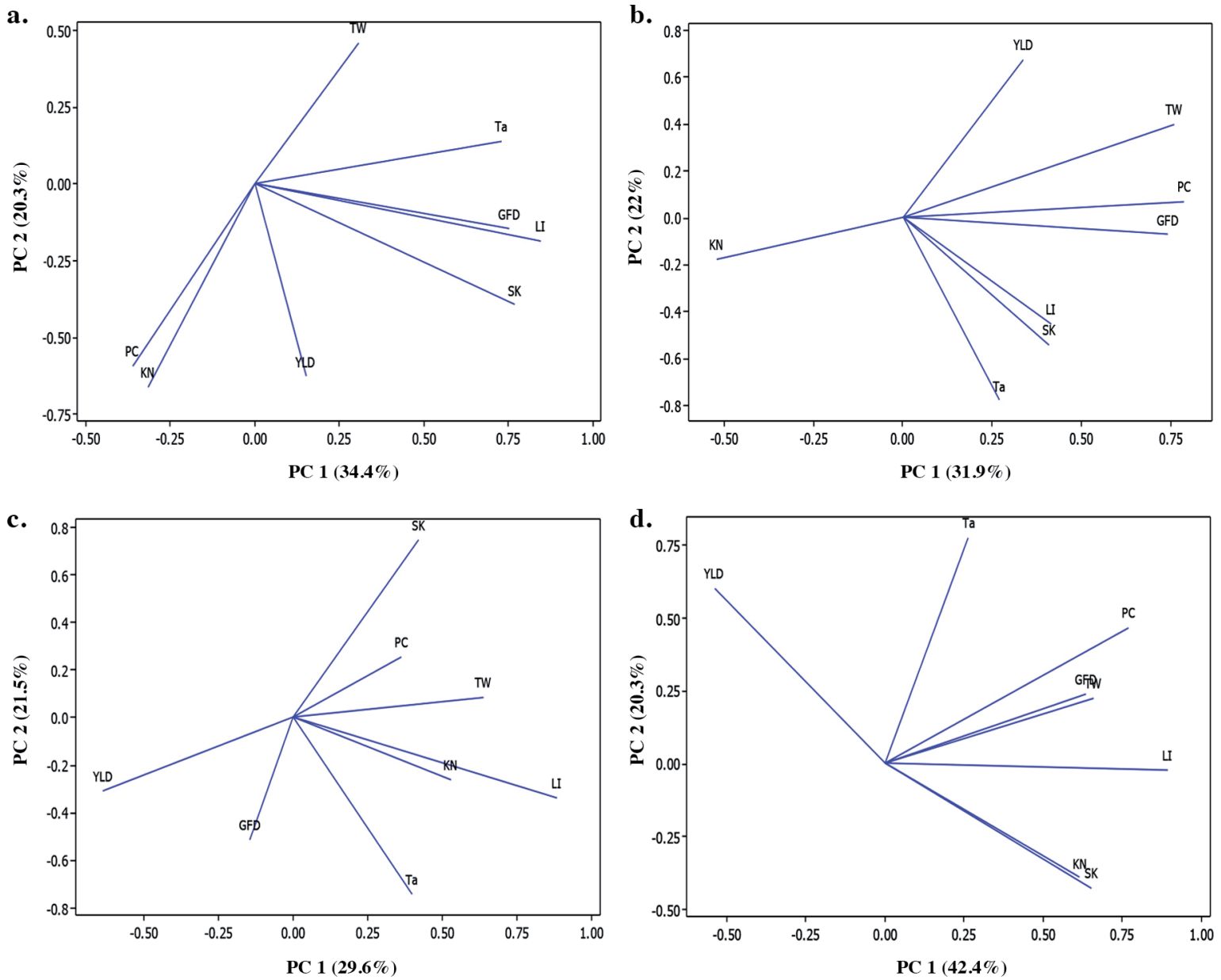

YLD: Grain yield; PC: protein content; TW: test weight; GFD: grain filling duration; LI: length of uppermost internode; SK: number of sterile kernels; KN: number of fertile kernels; Ta: average mean temperature.

\section{CONCLUSIONS}

Terminal stress simulated by the removal of all leaf blades $7 \mathrm{~d}$ after heading caused a significant $(\mathrm{P}<0.05)$ reduction of protein content (PC) and grain yield (YLD) in two-row genotypes, and PC, YLD, and test weight (TW) in six-row barley genotypes. The reduction of YLD and PC was greater in the group of six-row genotypes, suggesting that this type is more sensitive to terminal drought stress than two-row barley genotypes. Our results showed that two-row genotypes had both high YLD and PC under both optimal and drought stress conditions. On the other hand, this was not possible in the group of six-row genotypes due to a strong negative correlation between these traits. Generally, to select genotypes of both barley types with high PC under stress conditions, the priority should be for those genotypes with high TW, longer uppermost internode, and the longest grain filling period.

\section{ACKNOWLEDGEMENTS}

This work was supported by the Serbian Ministry of Education, Science and Technological Development under Grant TR 31005. 


\section{REFERENCES}

Afshari-Behbahanizadeh, S., Akbari, G.A., Shahbazi, M., Alahdadi, I., Farahani, L., Tabatabaee, S.A., et al. 2016. Qualitative and physical properties of barley grains under terminal drought stress conditions. Journal of Agricultural Science and Technology 18:1303-1317.

Alqudah, A., and Schnurbusch, T. 2014. Awn primordium to tipping is the most decisive developmental phase for spikelet survival in barley. Functional Plant Biology 41:424-436. https://doi.org/10.1071/FP13248.

Arisnabarreta, S., and Miralles, D.J. 2006. Floret development and grain setting in near isogenic two- and six-rowed barley lines (Hordeum vulgare L.) Field Crops Research 96:466-476. https://doi.org/10.1016/j.fcr.2005.09.004.

Arisnabarreta, S., and Miralles, D.J. 2008. Critical period for grain number establishment of near isogenic lines of two- and sixrowed barley. Field Crops Research 107(3):196-202.

Bratkovic, K. 2014. Genetic analysis of yield two row and six row barley application of method of multivariate analysis. PhD thesis. 205 p. University of Belgrade, Belgrade, Serbia.

Dias, A., and Lidon, F. 2009. Evaluation of grain filling rate and duration in bread and durum wheat, under heat stress after anthesis. Journal of Agronomy and Crop Science 195:137-147.

Distelfeld, A., Avni, R., and Fischer A.M. 2014. Senescence, nutrient remobilization, and yield in wheat and barley. Journal of Experimental Botany 65(14):3783-3798. https://doi.org/10.1093/jxb/ert477.

Djekic, V., Popovic, V., Brankovic, S., Terzic, D., and Djuric, N. 2017. Grain yield and yield components of winter barley. Agriculture and Forestry 63(1):179-185. https://doi.org/10.17707/AgricultForest.63.1.21.

Dodig, D., Kandic, V., Zoric, M., Nikolic-Dorić, E., Nikolic, A., Mutavdzic, B., et al. 2018. Comparative kernel growth and yield components of two- and six-row barley (Hordeum vulgare) under terminal drought simulated by defoliation. Crop and Pasture Science 69:1215-1224.

Dodig, D., Rancic, D., Vucelic Radovic, B., Zoric, M., Savic, J., Kandic, V., et al. 2017. Response of wheat plants under postanthesis stress induced by defoliation: II. Contribution of peduncle morpho-anatomical traits and carbon reserves to grain yield. The Journal of Agricultural Science 155(3):475-493. https://doi.org/10.1017/S0021859616000551.

Dodig, D., Savic, J., Kandic, V., Zoric, M., Vucelic Radovic, B., Popovic, A., et al. 2016. Responses of wheat plants under postanthesis stress induced by defoliation: I. Contribution of agro-physiological traits to grain yield. Experimental Agriculture 52(2):203-223. https://doi.org/10.1017/S0014479715000034.

Elia, M., Swanston, J.S., Moralejo, M., Molina-Cano, J.L., Thomas, W.T.B., Smith, P.L., et al. 2010. A model of the genetic differences in malting quality between European and North American barley cultivars based on a QTL study of the cross Triumph $\times$ Morex. Plant Breeding 129(3):280-290. https://doi.org/10.1111/j.1439-0523.2009.01694.x.

Frégeau-Reid, J., Choo, T.M., Ho, K.M., Martin, R., and Konishi, T. 2001. Comparisons of two-row and six-row barley for chemical composition using doubled-haploid lines. Crop Science 41:1737-1743. https://doi.org/10.2135/cropsci2001.1737.

Gonzalez, A., Martin, I., and Luis, A. 2007. Response of barley genotypes to terminal soil moisture stress: phenology, growth, and yield. Australian Journal of Agricultural Research 58:29-37. https://doi.org/10.1071/AR06026.

Grigorieva, E.A., Matzarakis, A., and de Freitas, C.R. 2010. Analysis of growing degree-days as a climate impact indicator in a region with extreme annual air temperature amplitude. Climate Research 42:143-154. https://doi.org/10.3354/cr00888.

Gupta, M., Abu-Ghannam, N., and Gallaghar, E. 2010. Barley for brewing. Characteristic changes during malting, brewing and applications of its by-products. Comprehensive Reviews in Food Science and Food Safety 9:318-328. https://doi.org/10.1111/j.1541-4337.2010.00112.x

Ibrahim, A., Harrison, M., Meinke, H., Fan, Y., Johnson, P., and Zhou, M. 2018. A regulator of early flowering in barley (Hordeum vulgare L.) PLOS ONE 13(7):e0200722. https://doi.org/10.1371/journal.pone.0200722.

Ingvordsen, C.H., Gislum, R., Jorgensen, J.R., Mikkelsen, T.N., Stockmarr, A., and Jorgensen, R.B. 2016. Grain protein concentration and harvestable protein under future climate conditions. A study of 108 spring barley accessions. Journal of Experimental Botany 67(8):2151-2158. https://doi.org/10.1093/jxb/erw033.

Kandic, V., Dodig, D., Zoric, M., Nikolic, A., Surlan Momirovic, G., Kaitovic, Z., et al. 2018. Grain filling parameters of two- and six-rowed barley genotypes in terminal drought conditions. Italian Journal of Agrometeorology 23(2):5-14. https://doi.org/10.19199/2018.2.2038-5625.005.

Kohl, H.S. 2015. N remobilisation during barley grain filling and the influence of sink-strength alteration in developing wheat grains 115 p. PhD thesis. Naturwissenschaftliche Fakultät I - Biowissenschaften der Martin-Luther-Universität HalleWittenberg, Halle, Germany.

Koppolu, R., Anwar, N., Sakuma, S., Tagiri,A., Lundqvist, U., et al. 2013. Six-rowed spike4 (Vrs4) controls spikelet determinacy and row-type in barley. Proceedings of the National Academy of Sciences of the United States of America 110(32):1319813203. https://doi.org/10.1073/pnas.1221950110.

Lahouar, L., Ghrairi, F., El Arem, A., Medimagh, S., El Felah, M., Sale, H.B., et al. 2017. Biochemical composition and nutritional evaluation of barley Rihane (Hordeum vulgare L.) African Journal of Traditional, Complementary and Alternative Medicines 14(1):310-317. 
Lang, L., Rakszegi, M., and Bedo, Z. 2013. Cereal production and its characteristics. Engineering aspects of cereal and cerealbased products. CRC Press, Boca Raton, Florida, USA.

Merah, O., Evon, P., and Monneveux, P. 2017. Participation of green organs to grain filling in Triticum turgidum var. durum grown under Mediterranean conditions. International Journal of Molecular Sciences 19:56. https://doi.org/10.3390/ijms19010056.

Modarresi, M., Mohammadi, V., Zali, A., and Mardi, M. 2010. Response of wheat yield and yield related traits to high temperature. Cereal Research Communications 38(1):23-31. https://doi.org/10.1556/CRC.38.2010.1.3.

Moody, D., Flood, R., and Fettell, N. 2001. Influence of BVP on grain size and yield in southern Australia. $10^{\text {th }}$ Australian Barley Technical Symposium, Canberra, Australia. 16-20 September. Australian Barley Technical Symposium Incorporated, Canberra, Australia.

Newton, A.C., Flavell, A.J., George, T.S., Leat, P., Mullholland, B., Ramsay, L., et al. 2011. Crops that feed the world 4. Barley: a resilient crop? Strengths and weaknesses in the context of food security. Food Security 3:141-178. https://doi.org/10.1007/s12571-011-0126-3.

Nikkhah, H.R., Saberi, M.H., and Mahlouji, M. 2010. Study of effective traits on grain yield of two and six row barley genotypes (Hordeum vulgare L.) under terminal drought stress conditions. Iranian Journal of Crop Sciences 12(2):170-184.

Nuttall, J.G., O’Leary, G.J., Panozzo, J.F., Walker, C.K., Barlow, K.M., and Fitzgerald, G.J. 2017. Models of grain quality in wheat-A review. Field Crops Research 202:136-145. https://doi.org/10.1016/j.fcr.2015.12.011.

Reinhardt, D., Jansen, G., Seddig, S., and Eichler-Löbermann, B. 2013. Temperature stress during flowering time affects yield and quality parameters of waxy barley. Applied Agricultural and Forestry Research (63)79-84. https://doi.org/10.3220/LBF_2013_79-84.

Sakuma, S., Lundqvist, U., Kakei, Y., Thirulogachandar, V., Suzuki, T., et al. 2017. Extreme suppression of lateral floret development by a single amino acid change in the VRS1 transcription factor. Plant Physiology 175(4):1720-1731. https://doi.org/10.1104/pp.17.01149.

Samarah, N., Alqudah, A., Amayreh, J., and McAndrews, G. 2009. The effect of late terminal drought stress on yield components of four barley cultivars. Journal of Agronomy and Crop Science 195:427441. https://doi.org/10.1111/j.1439-037X.2009.00387.x.

Scofield, G.N., Ruuska, S.A., Aoki, N., Lewis, D.C., Tabe, L.M., and Jenkins, C.L.D. 2009. Starch storage in the stems of wheat plants: localization and temporal changes. Annals of Botany 103(6):859-868. https://doi.org/10.1093/aob/mcp010.

Shobbar, Z.S., Shahbazi, M., and Tafreshi, R.S. 2017. Barley stem reserves and yield maintenance under terminal drought: molecular dissection of fructan biosynthesis and remobilization. Journal of Plant Physiology and Pathology 5(5):68. https://doi.org/10.4172/2329-955X-C1-011.

Wu, X., Cai, K., Zhang, G., and Zeng, F. 2017. Metabolite profiling of barley grains subjected to water stress: To explain the genotypic difference in drought-induced impacts on malting quality. Frontiers in Plant Science 8:1547. https://doi.org/10.3389/fpls.2017.01547.

Yan, W., and Rajcan, I. 2002. Biplot analysis of test sites and trait relations of soybean in Ontario. Crop Science 42:11-20. https://doi.org/10.2135/cropsci2002.0011.

Zadoks, J.C., Chang, T.T., and Konzak, C.F. 1974. A decimal code for the growth stages of cereals. Weed Research 14:415-421 https://doi.org/10.1111/j.13653180.1974.tb01084.x.

Zwirek, M., Waugh, R., and McKim, S.M. 2019. Interaction between row type genes in barley controls meristem determinacy and reveals novel routes to improved grain. New Phytologist 221:1950-1965. https://doi.org/10.1111/nph.15548. 